\title{
Novel technique for static and dynamic shear testing of Ti6Al4V sheet
}

\author{
J. Peirs, P. Verleysen, W. Van Paepegem and J. Degrieck \\ Department of Materials Science and Engineering, Ghent University, Sint-Pietersnieuwstraat 41, 9000 Gent, \\ Belgium \\ Jan.Peirs@UGent.be, Tel: 0032926434 36, Fax: 003292643587
}

\begin{abstract}
Few shear test techniques exist that cover the range of strain rates from static to dynamic. In this work, a novel specimen geometry is presented that can be used for the characterisation of the shear behaviour of sheet metals over a wide range of strain rates using traditional tensile test devices. The main objectives during the development of the shear specimen have been 1) obtaining a homogeneous stress state with low stress triaxiality in the zone of the specimen subjected to shear and 2) appropriateness for dynamic testing. Additionally, avoiding premature specimen failure due to edge effects was aimed at. Most dimensional and practical constraints arose from the dynamic test in which the specimen is loaded by mechanical waves in a split Hopkinson tensile bar device. Design of the specimen geometry is based on finite element simulations using ABAQUS/Explicit. The behaviour of the specimen is compared with the more traditionally used simple shear specimen with clamped grips. Advantages of the new technique are shown.

The technique is applied to Ti6Al4V sheet. During the high strain rate experiments high speed photography and digital image correlation are used to obtain the local shear strain in the specimen. Comparison of experimental and numerical results shows good correspondence.
\end{abstract}

Keywords - shear test, split Hopkinson bar, high strain rate, Ti6Al4V, triaxiality

\section{INTRODUCTION}

For a fundamental understanding of the plastic yield behaviour of metals, experimental characterisation of the shear behaviour is essential. Indeed, regardless of the loading mode ductile materials basically deform plastically in shear. Also many applications exist in which metals are, statically or dynamically, loaded in shear (e.g. machining, punching, extrusion, impact...).

Shear tests not only provide a fundamental loading mode, they also have distinct advantages over the more frequently used uni-axial tensile and compression tests. Unlike uni-axial tensile experiments where material failure results from highly localized deformations after necking, a shear test can be used to identify failure parameters due to ductile fracture and not instability. No thinning occurs in a well-designed shear specimen, thus diffuse and localized necking is avoided. Damage growth is retarded because of the lower stress triaxiality and, generally, larger strains, including stage IV hardening, can be reached in shear tests, by which better material modelling is achieved [1-3]. Materials susceptible to shear localization, however, fail at lower deformations. For such materials, shear tests are useful to study the mechanisms leading to shear localization, such as adiabatic shear banding. Since there is no cross section reduction in a material sample subjected to shear, an unambiguous relation exists between true and engineering values of the stress.

Despite the numerous advantages, shear testing of materials is not straightforward. Many experimental techniques have been developed to load materials in shear. For sheet materials, the simple shear test is the most commonly used. In this test, a rectangular specimen is mechanically clamped at two sides, and the shear deformation is applied by moving the clamps parallel to each other in opposite directions. The simple shear test and many variants have been used to study the static [4-11] and dynamic $[4,3,12,13,9]$ behaviour of a large number of materials. For dynamic experiments most often a split Hopkinson bar or direct impact Hopkinson bar setup is used with a symmetrical version of the simple shear specimen: the double shear specimen. The double shear specimen has two shear regions to maintain an axial loading in the setup. Comprehensive studies on this technique can be found in the papers of Klepaczko and co-workers $[3,4,9,14,15]$. Despite the good results that have been obtained, the simple shear and double shear test have some shortcomings. In addition to shear, also tensile and compression stress components exist in the shear region. Uncontrolled specimen deformation is likely to occur in the clamps. Frequently, buckling and cracking arises at the borders of the shear region, leading to an early specimen failure initiated at the edges, instead of the targeted failure in the central part of the specimen [16]. Moreover, by using the double shear specimen an average of the material behaviour in two shear regions is obtained. On top of that, for dynamic experiments 
where the specimen is loaded by mechanical waves, as is the case in split Hopkinson bar devices, the mechanical devices (clamps, screws, ...) used to fix the specimen induce errors. Indeed, the waves interact with the clamps and both the deformation and force applied to the specimen, as well as the measurements are affected. The influence of clamps on the test results can be reduced by using larger diameter Hopkinson bars [12] or a direct impact Hopkinson bar setup in combination with an advanced optical extensometer for measurement of the specimen displacement [3].

The aim of the study presented here is the development of an alternative sheet specimen geometry that can be used for static and dynamic tests. The proposed specimen geometry is essentially based on the geometries for static experiments of Bao and Wierzbicki [17], used to study the influence of stress triaxiality on fracture, and Tarigopula et al. [1], used to study large plastic deformation. Starting from a geometry which fulfils the mainly dimensional requirements imposed by the dynamic tests, the specimen geometry proposed here is optimised with respect to stress homogeneity and triaxiality by means of finite element (FE) simulations. The performance of the specimen is compared with the simple shear test with clamped grips. Afterwards, the optimized specimen is used to characterize the shear behaviour of titanium alloy Ti6Al4V. This material was chosen because of its popularity for aerospace structures where impact resistance is important [18].

\section{METHODOLOGY}

\subsection{Experimental setups}

For both the static and high strain rate shear experiments tensile setups are used. The specimen geometry is designed such that the applied tensile load is converted to shear stress in the gage section of the specimen. The dynamic tests are carried out on a tensile split Hopkinson bar (SHB) setup [19,20]. The setup basically consists of two aligned bars with the specimen placed in between and glued into slots. A tensile stress wave, generated at the free end of the input bar by impact of a projectile, propagates along the input bar towards the specimen. This wave interacts with the specimen and is partly reflected back into the input bar and partly transmitted into the output bar. The strain histories corresponding to the loading, reflected and transmitted wave $\left(\varepsilon_{\mathrm{i}}, \varepsilon_{\mathrm{r}}\right.$ and $\left.\varepsilon_{\mathrm{t}}\right)$ are measured by means of strain gauges on the Hopkinson bars. From those waves, the total force and elongation history of the specimen is determined, based on the principles of one-dimensional elastic-wave propagation in slender bars [19]. Strain rates achieved with the Hopkinson technique are typically in the order of $10^{3} \mathrm{~s}^{-1}$. The setup used in this study has aluminium (A15083) bars with lengths of $6 \mathrm{~m}$ and $3.125 \mathrm{~m}$, and a diameter of $25 \mathrm{~mm}$.

For the static tests a traditional tensile test device is used. In order to have the same boundary conditions as in the high strain rate experiments, the specimen is glued in slots of aluminium bars with a diameter of $25 \mathrm{~mm}$ (Fig.1). The bars are clamped in the test bench. During the experiment the clamps separate with a velocity of $0.0033 \mathrm{~mm} / \mathrm{s}$. A load cell is measuring the applied load. The relative displacement of the specimen/bar interfaces is calculated as average of the displacements measured by three LVDTs placed around the specimen.

During both the static and dynamic experiments, images are taken of the deforming specimen with a Photron APX-RS digital high speed camera. For the static experiments a high resolution Pixelink camera is used as well. The images enable a better interpretation of the test results and are used to assess of the local strains in the specimen. Either a speckle pattern or a line grid is put on the specimen surface to assess the local deformation. 


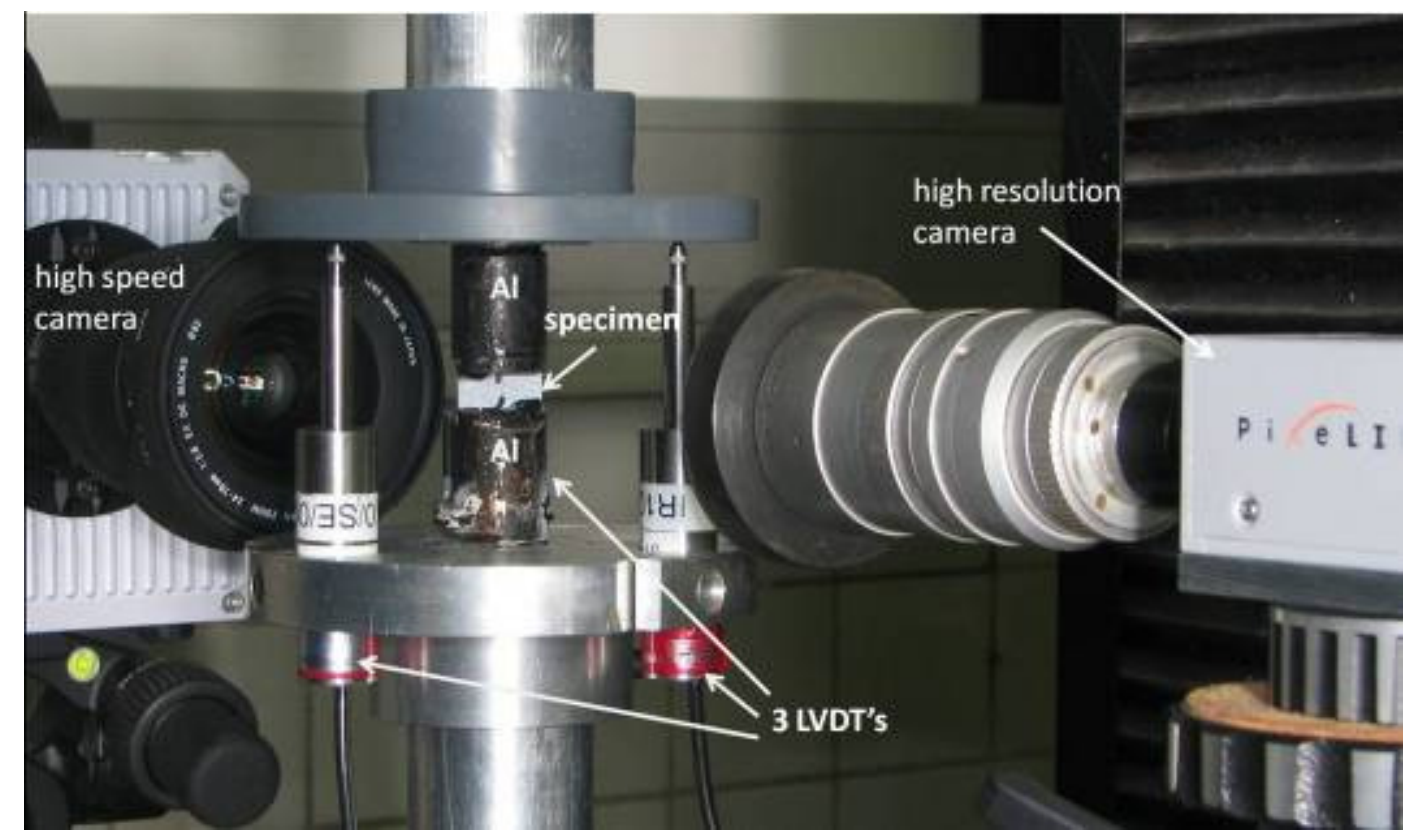

Fig.1 Static shear test. The LVDTs measure the displacement between the two discs

\subsection{Shear specimen requirements}

When optimizing the sheet shear geometry, fulfilment of the following requirements is aimed at:

1. a state of pure shear stress in the shear region. This can be assessed using the stress triaxiality $\eta$, i.e. the ratio of hydrostatic stress to von Mises stress. For a pure shear stress state the stress triaxiality is 0 ,

2. homogeneity of the stress and strain along the shear region,

3. straightforward relation between measured force and shear stress, thus allowing extraction of the local stress in the shear zone from the measured force,

4. negligible effect of the boundary conditions on the stress and strain in the shear region,

5. completely in-plane deformation,

6. easy and reproducible manufacturing of the specimen.

For reasons of comparability, the use of the same geometry in both the static and dynamic experiments is preferred. Additional demands arise from the high strain rate tests:

7. fast establishment of a state of quasi-equilibrium in the specimen,

8. no use of clamps, screws, ..., or more generally tools that could disturb the waves in the Hopkinson bars, to fix the specimen in the device. Indeed, these tools not only introduce oscillations in the force and elongation history of the specimen, but also affect the force and elongation measurement,

9. load and displacement in line with the bars. Parasitic non-axial forces or moments give rise to an uncontrollable, non-axial displacement of the specimen/bar interfaces.

Meeting all requirements simultaneously is impossible because fulfilment of one often opposes fulfilment of the other. A robust clamping device, for example, could theoretically be used to have a homogeneously distributed shear strain in a confined region (criterion 2), however, it cannot be used for dynamic experiments (criteria 8 and 9). The effect of boundary conditions and edge effects could be reduced by increasing the size of the shear zone (criterion 4), however, the time needed to reach quasi-static equilibrium in the specimen is proportional with twice the length of the specimen and consequently for longer specimens it takes more time to reach the desired equilibrium (criterion 7). For too long specimens no equilibrium is established. Thinning the specimen in the shear region [17,21] could be used to ensure that only material in the shear region deforms plastically, in this way simplifying the calculation of the strain from the elongation (criterion 3), but, apart from consideration related to internal stresses, this certainly complicates production of the specimen (criterion 6), especially for specimens made out of thin sheets. 
The starting point for the shear specimen are the geometries described in $[1,17]$ and presented in Fig. 2. For both specimens, an applied tensile load gives rise to shear stresses around the centre of the specimen. These specimens are used for static material characterization and cannot be used as such for high strain rate testing essentially because their dimensions are too large (criterion 7) and the system used to fix the specimen in the test device cannot be used in a dynamic experiment (criterion 8). Simply gluing the specimen in slits of the Hopkinson bars instead of using pins would introduce non-axial forces on the bars (criterion 9).

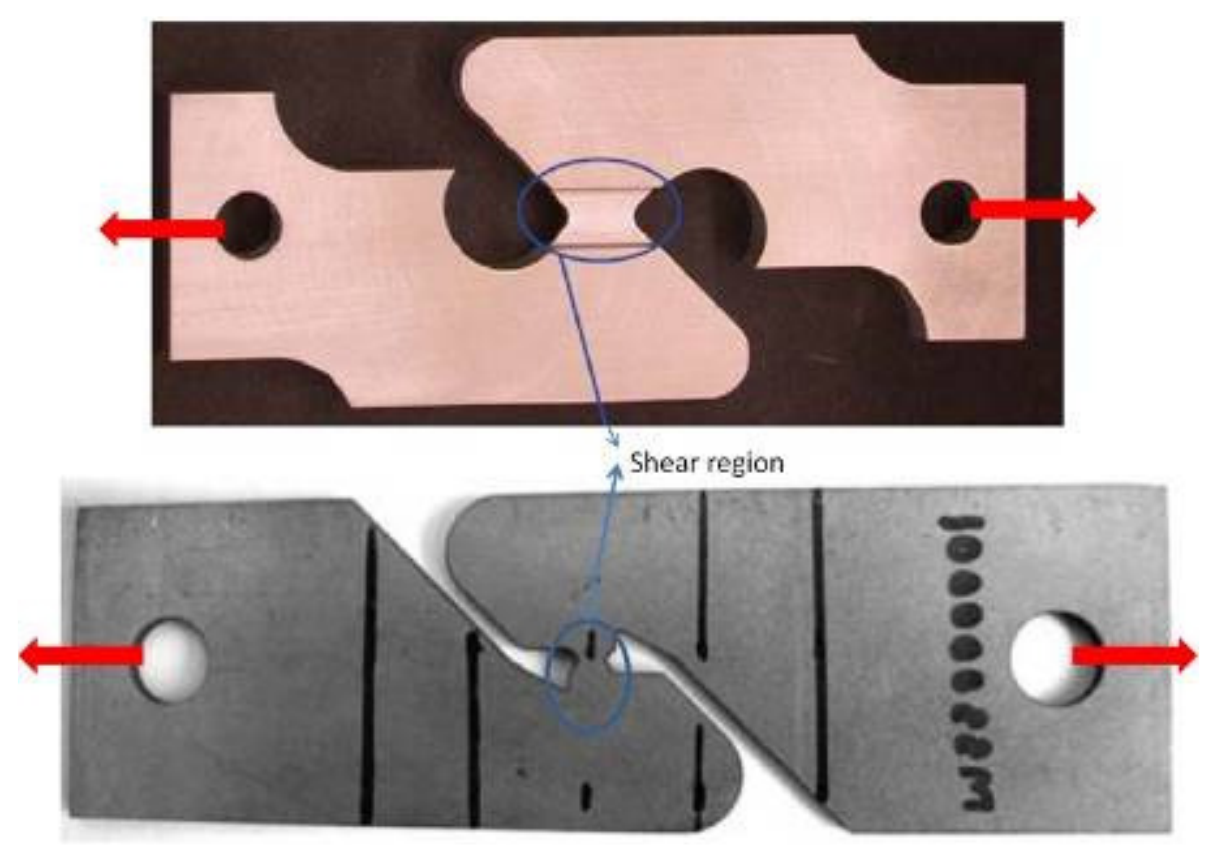

Fig. 2 Shear specimen geometries from [17] and [1]

\subsection{Finite element simulations}

Several geometrical parameters of the shear specimen geometry have been varied by means of numerical FEsimulations. For each variant, the requirements listed above are checked. Important parameters include: the size and geometry of the free edges of the shear region (denoted as notches hereafter), notch position, length and width of the shear region and overall dimensions of the specimen. Only a selection of the relevant simulation results is discussed in the next sections.

For the optimization of the geometry, 2D finite element models of the specimens are built in ABAQUS/Explicit. Plane stress elements are used because primarily thin sheets are considered. However, for the final specimen geometry 3D simulations are performed to check if there is no out of plane deformation. For the sheet material an elasto-plastic model is used. Effects of strain-rate and temperature on the isotropic hardening behaviour of the material are taken into account by the Johnson-Cook model [22].

$$
\sigma=\left[A+B \varepsilon_{p}^{n}\left[1+C \ln \frac{\dot{\varepsilon}}{\dot{\varepsilon}_{0}}\right]\left[1-\left(\frac{T-T_{\text {room }}}{T_{\text {melt }}-T_{\text {room }}}\right)^{m}\right]\right.
$$

The five material parameters for Ti6Al4V are based on results from compression tests [23]: $\mathrm{A}=1120 \mathrm{MPa}$, $\mathrm{B}=667 \mathrm{MPa}, \mathrm{C}=0.027, \mathrm{~m}=1.33, \mathrm{n}=0.47$. Adiabatic heating by plastic work is included in the model of the dynamically loaded specimens. The quasi-adiabatic temperature increase in the specimen during high strain rate plastic deformation is calculated using the following formula:

$$
\Delta T=\frac{\beta}{\rho c} \int \sigma d \varepsilon_{p}
$$

In this equation, $\rho$ is the mass density, $\mathrm{c}$ the specific heat and $\beta$ the Taylor-Quinney coefficient indicating the fraction of plastic work converted into heat. This $\beta$-value is usually assumed to have a value between 0.9 and 1 [24], here 0.9 is used. 
Strain values calculated by Abaqus are logarithmic Euler strains: $\mathbf{E}=\ln (\mathbf{V})$ with $\mathbf{V}^{2}=\mathbf{F F}^{\mathrm{T}}$ the left stretch tensor and $\mathbf{F}$ the deformation gradient. The deformation gradient $\mathbf{F}$ describes the relative spatial position of two neighbouring particles after deformation $\mathbf{x}$ in terms of their relative material position before deformation $\mathbf{x}_{\mathbf{0}}$ : $\mathbf{F}=\partial \mathbf{x} / \partial \mathbf{x}_{0}=\mathrm{I}+\partial \mathbf{u} / \partial \mathbf{x}_{0}$ with $\mathbf{u}$ the displacement vector [25]. Because the eigenvalues of $\mathbf{F}$ are the principal stretches $\lambda_{\mathrm{i}}$, the logarithmic strain can be written as:

$$
E=\ln (V)=\sum_{i=1}^{3} \ln \left(\lambda_{i}\right) n_{i} n_{i}^{T}
$$

With $\mathrm{n}_{\mathrm{i}}$ the principal stretch directions in the current configuration. The advantage of working with logarithmic strain values is that equal compressive and tensile strains are represented by the same value but opposite sign of the strain. In this work the logarithmic shear strain component is referred to as $\mathrm{e}_{12}$. For the case of in-plane simple shear the deformation gradient takes the form:

$$
F=\left[\begin{array}{ll}
1 & \gamma \\
0 & 1
\end{array}\right]
$$

With $\gamma$ the shear angle which is often used as a strain measure and defined as the ratio of the shear displacement and the shear region with $\Delta \mathrm{u} / \mathrm{w}$. The logarithmic shear strain component in simple shear, calculated with (3) becomes:

$$
e_{12}=\frac{\ln \left(2+\gamma^{2}+\gamma \sqrt{4+\gamma^{2}}\right)-\ln \left(2+\gamma^{2}-\gamma \sqrt{4+\gamma^{2}}\right)}{2 \sqrt{4+\gamma^{2}}}
$$

Only for small strains $2 \mathrm{e}_{12} \approx \gamma$, for larger strains $\mathrm{e}_{12}<\gamma / 2$. For simple shear $\mathrm{e}_{12}$ has a maximum value of $66 \%$ for $\gamma \approx 3$.

\section{SPECIMEN OPTIMIZATION}

\subsection{Geometry of the shear zone}

In a simple shear test the specimen is fixed in clamps often by using bolts. By moving the clamps parallel to each other in opposite direction, a shear load is applied to the shear zone. For the specimens of Fig. 2 the material next to the shear region transfers the test load to the shear region. To guarantee stress and strain homogeneity in the shear zone, deformation of the material adjacent to the shear zone should be limited. The shear region is defined by its length, shape and size of the notches and, very important, the position of the notches against the axis of symmetry.

\section{Notch shape}

Based on specimens found in literature [15] three notch geometries are considered: a straight notch, a round notch and a butterfly notch. Fig. 4 shows the shear strain distribution across the width of the shear region in the centre of the specimen when a deformation $\Delta \mathrm{u}$ is imposed corresponding with a shear angle $(\gamma=\Delta \mathrm{u} / \mathrm{w})$ of approximately 0.96 . The geometric width of the shear zone, determined by the size of the notches, is $1 \mathrm{~mm}$. The theoretic logarithmic shear strain on the figure is calculated with expression (5). For a perfectly clamped specimen, the strain distribution is very close to the theoretic simple shear strain distribution. However, as soon as clamping is not perfect, material adjacent to the geometrically defined shear zone deforms. In this more realistic case, the deformation is the lowest for the butterfly notch, the highest for the straight notch. The shear distribution for the rounded notch specimen is close to that of the sharp notch specimen. However, using rounded notches has additional advantages: lower stress concentration in the notch and a more reproducible manufacturing of the specimen. Therefore, a round notch is selected for the further design of the specimen. 


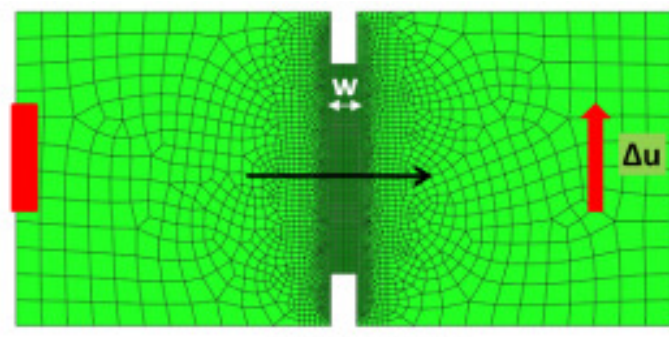

straight notch

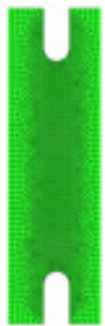

round

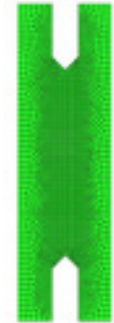

butterfly

Fig. 3 Different notch geometries. The path that is used for evaluation of the strain distribution represented in Figure 4 is shown

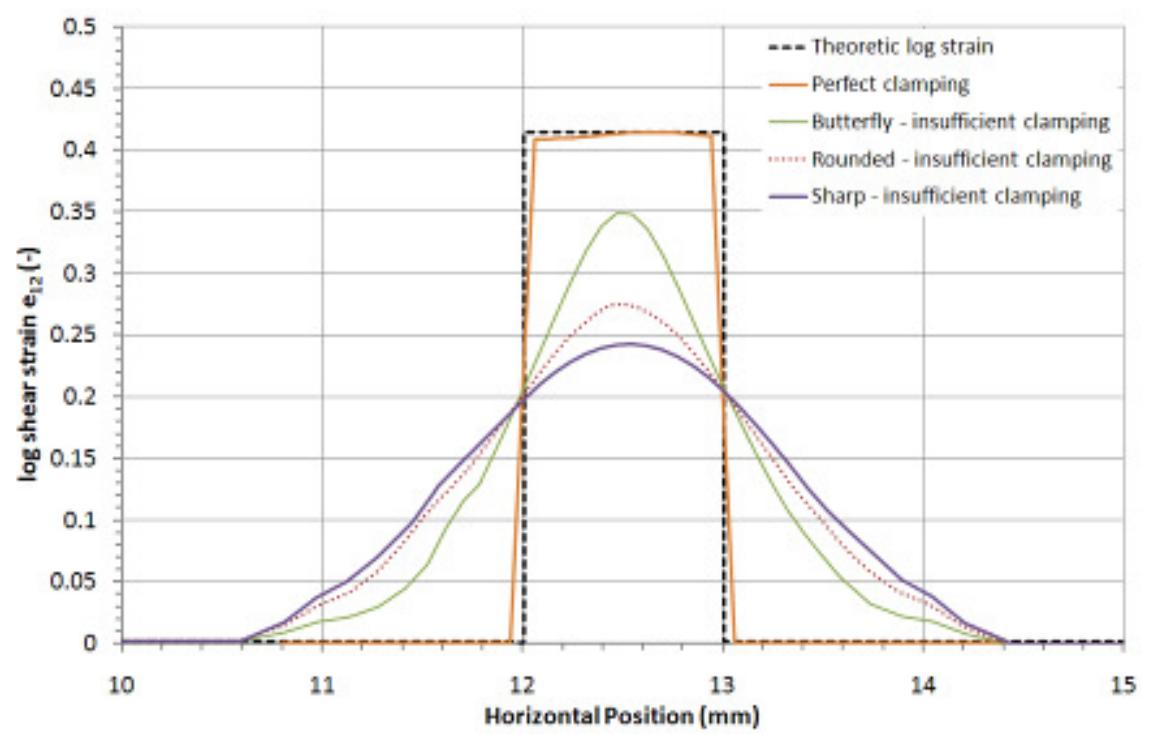

Fig. 4 Shear strain distribution across the width of the shear region for different notch geometries

\section{Width and length of the shear region}

Compared to static, simple shear experiments, where fulfilment of most criteria requires a sufficiently high length to width ratio of the shear region, selection of the optimal geometrical width $\mathrm{w}$ and length $\mathrm{L}$ of the shear region is more complicated for high strain rate experiments. In [4][26] a length-over-width ratio L/w of at least 10 is recommended in order to have a homogeneous shear stress distribution and negligible effects of the notches (criterion 1 and 5). However, a prerequisite for homogeneous stresses and strains in a dynamically loaded specimen is that a state of quasi-static equilibrium is established in the specimen (criterion 7), imposing limits to the total specimen length.

Moreover, the FE simulations show that, if no clamps are used, a small shear region length is beneficial for the stress and strain homogeneity in the shear region. In Fig. 5 the plastic equivalent strain distributions for specimens with lengths of $3 \mathrm{~mm}$ and $8 \mathrm{~mm}$ are presented. The shear strain along a line connecting the two notches is also presented. For both geometries, shear strains are low in a small zone around the notches. For larger lengths of the shear zone two strain peaks arise close to the notches causing early fracture of the specimen. The strain is clearly more homogeneous for lower L-values. Furthermore, it can be seen in Fig. 5 that for the specimen with large L, the highest plastic strains occur next to the notches outside the geometric shear region. Also to reduce the deformation of the material adjacent to the shear zone, a low test force, and thus again a reduced shear zone length, is preferred.

The width of the shear zone should be large enough in order to have a sufficiently representative sample of the material subjected to shear. A larger width also simplifies the use of optical methods to measure the strain and facilitates a reproducible manufacturing of the specimen. In case of a round notch the geometrical width is equal to twice the notch radius. The actual width of the shear region, however, is dependent on both the material behaviour and the specimen geometry and is consequently difficult to control. 

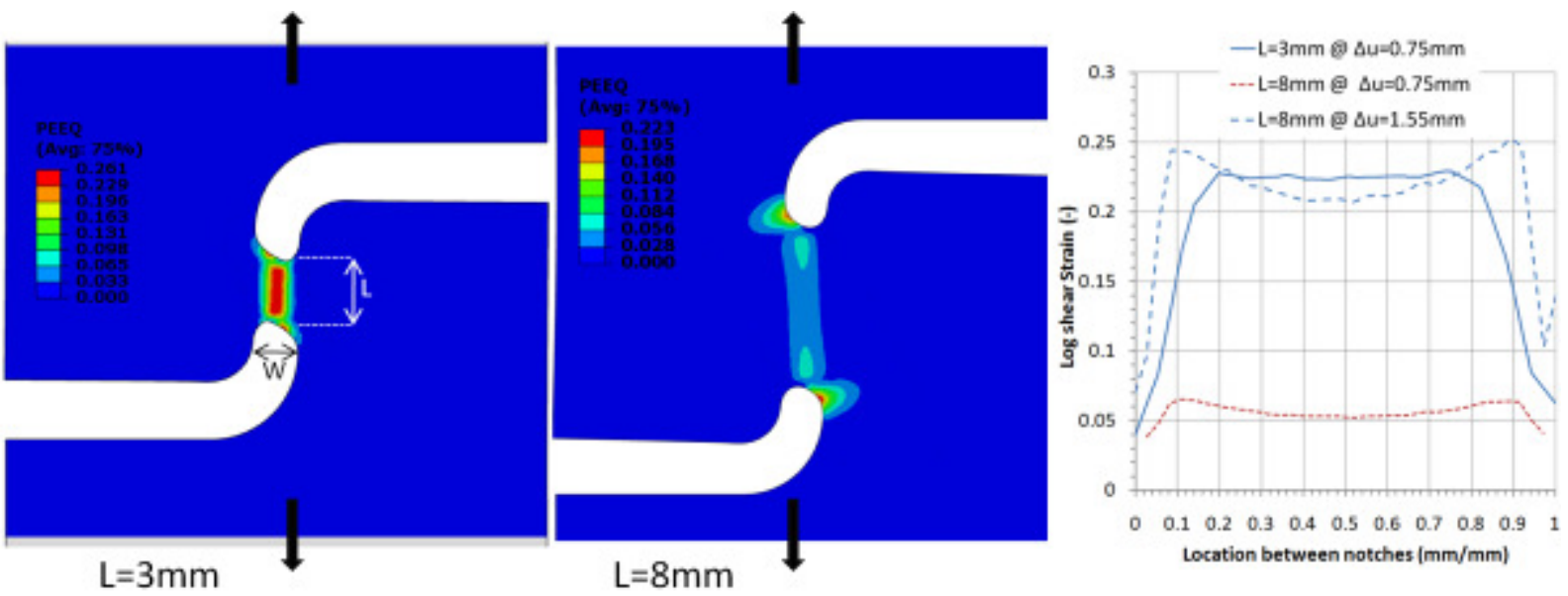

Fig. 5 Simulated equivalent plastic strain (PEEQ) and shear strain distribution in specimens with different length of shear region after total elongation of $0.75 \mathrm{~mm}$. Increasing the $\mathrm{L} / \mathrm{w}$ ratio does not improve the homogeneity of the shear strain distribution

\section{Notch position}

The numerical simulations show that the position of notches against the axis of symmetry has a major effect on the stress state in the shear region. Since a stress triaxiality close to zero is aimed at (criterion 1), the position of the notches is optimised to lower the stress triaxiality. Fig. 6 shows the stress triaxiality distribution for specimens with three different notch configurations at a specimen elongation $\Delta \mathrm{u}$ of $0.75 \mathrm{~mm}$. The first image shows a specimen with notches aligned with the tensile direction. The stress triaxiality in the centre of the shear region is approximately 0.1 , which means that stress components other than shear are quite important. The notch in the second image has an undercut, as can be found in the specimens of [1]. Here a triaxiality of 0.08 is reached in the centre; although the triaxiality is reduced by the undercut, normal stress components remain important in the shear zone. Also the tensile stress near the undercut increases. The third image shows a specimen with eccentric positioned notches $(\mathrm{e}=1 \mathrm{~mm})$. Here, the triaxiality is merely 0.01 .

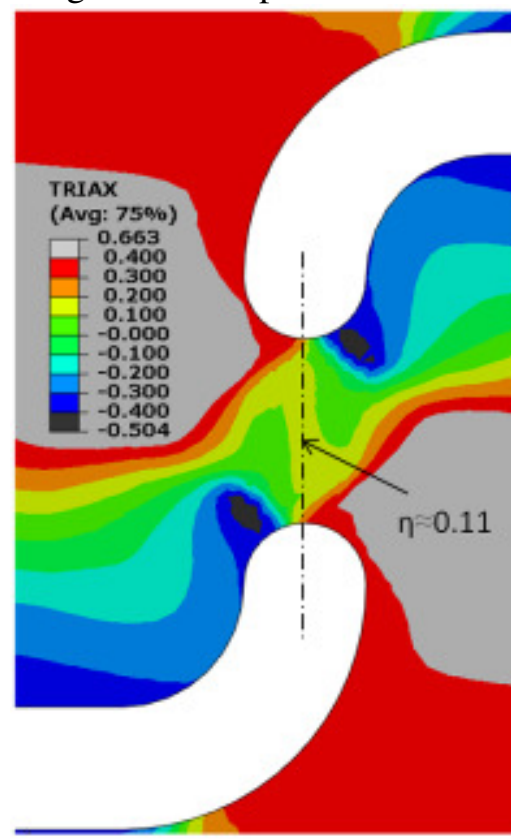

symmetric notch position

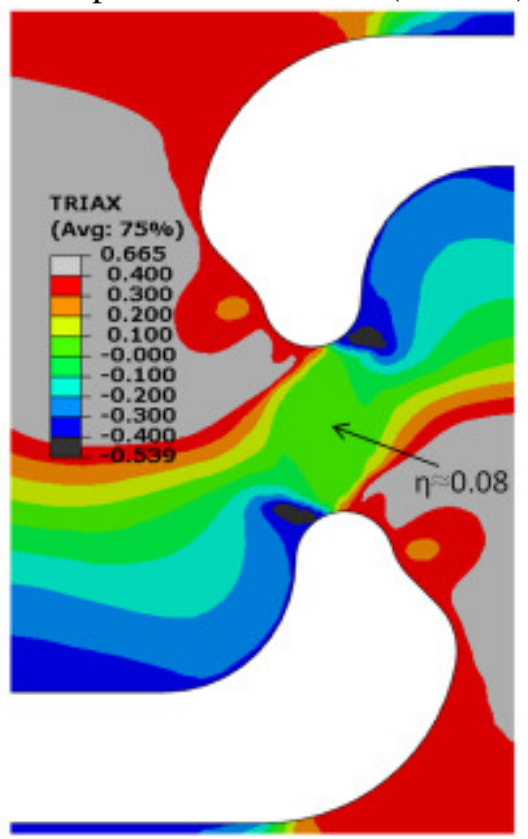

notch with undercut

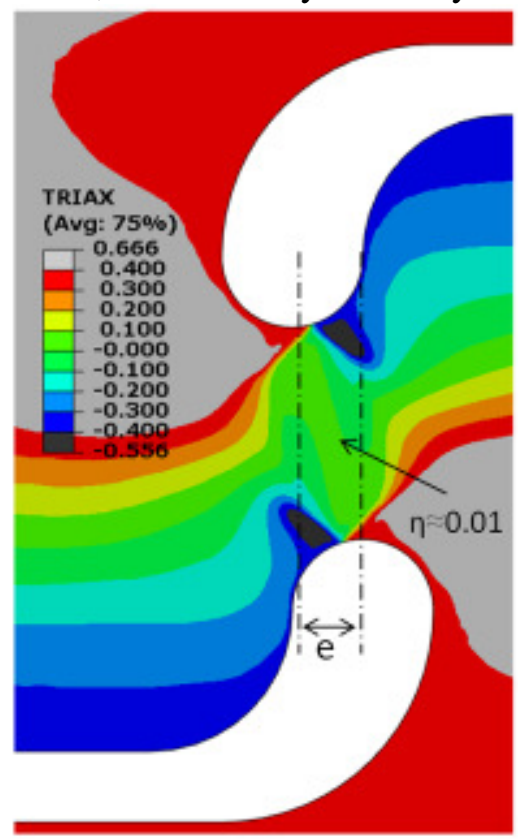

eccentric notch position

Fig. 6 Stress triaxiality (TRIAX) distribution for three different notch configurations: symmetric notch position, undercut and eccentric notch position. The lowest triaxiality is obtained with the eccentric notch position

The reduction of the triaxiality can be explained by the fact that an eccentric notch position causes a compressive stress in the shear region compensating for the tensile stress caused by elastic deformation of the material adjacent to the shear region. If the notches are placed symmetrically, next to the shear stress, also 
tensile stresses exist in the shear zone. The magnitude of eccentricity necessary to have a pure-shear stress state dependents on the overall geometry and the mechanical properties of the material. For materials with a higher Young's modulus, a lower eccentricity is required to reach a minimum in triaxiality. Indeed, the elastic specimen deformation outside the shear region is lower.

The distribution of the stress triaxiality along the shear region for different notch eccentricities is shown in Fig. 7 for a specimen with notch radius of $0.5 \mathrm{~mm}$. The triaxiality at the free edges of the shear region is $1 / 3$ because of the uni-axial stress state at that location. A region with constant level of triaxiality around the centre of the shear region exists. The figure clearly shows that the triaxiality strongly depends on the eccentricity. Eccentricities higher than 1 yield negative stress triaxiality, corresponding with a compressive stress state.

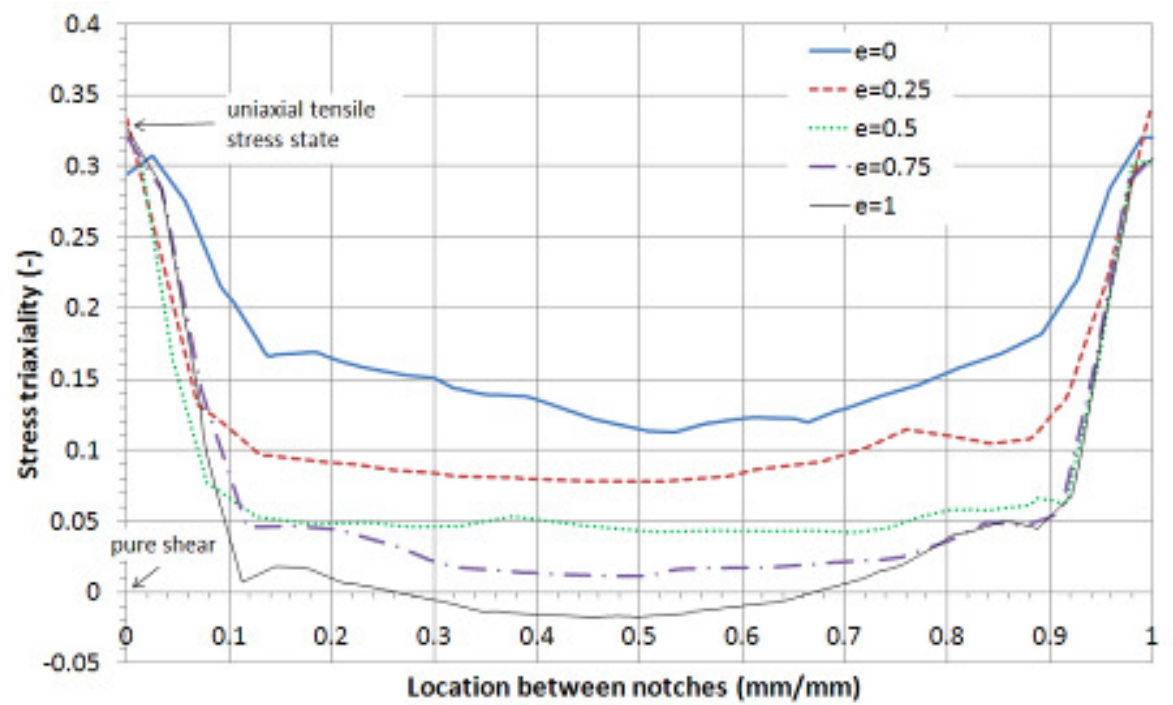

Fig. 7 Stress triaxiality along the shear line of specimens with notch eccentricities ranging from 0 to $1 \mathrm{~mm}$. The geometric width of the shear region is $1 \mathrm{~mm}$ in these simulations

The stress triaxiality evolves during the experiment. Fig. 8 shows the evolution of the average stress triaxiality as function of the shear strain for specimens without and with eccentric position of the notches. The highest values are reached during elastic deformation. In the specimen with eccentric positioned notches during plastic deformation a low and quite stable triaxiality is reached. At higher strains, the triaxiality tends to increase because of rotation of the shear region. It is found that the average value of the triaxiality during the plastic deformation is \pm 0.1 for the symmetric specimen and \pm 0.02 for the eccentric specimen. 


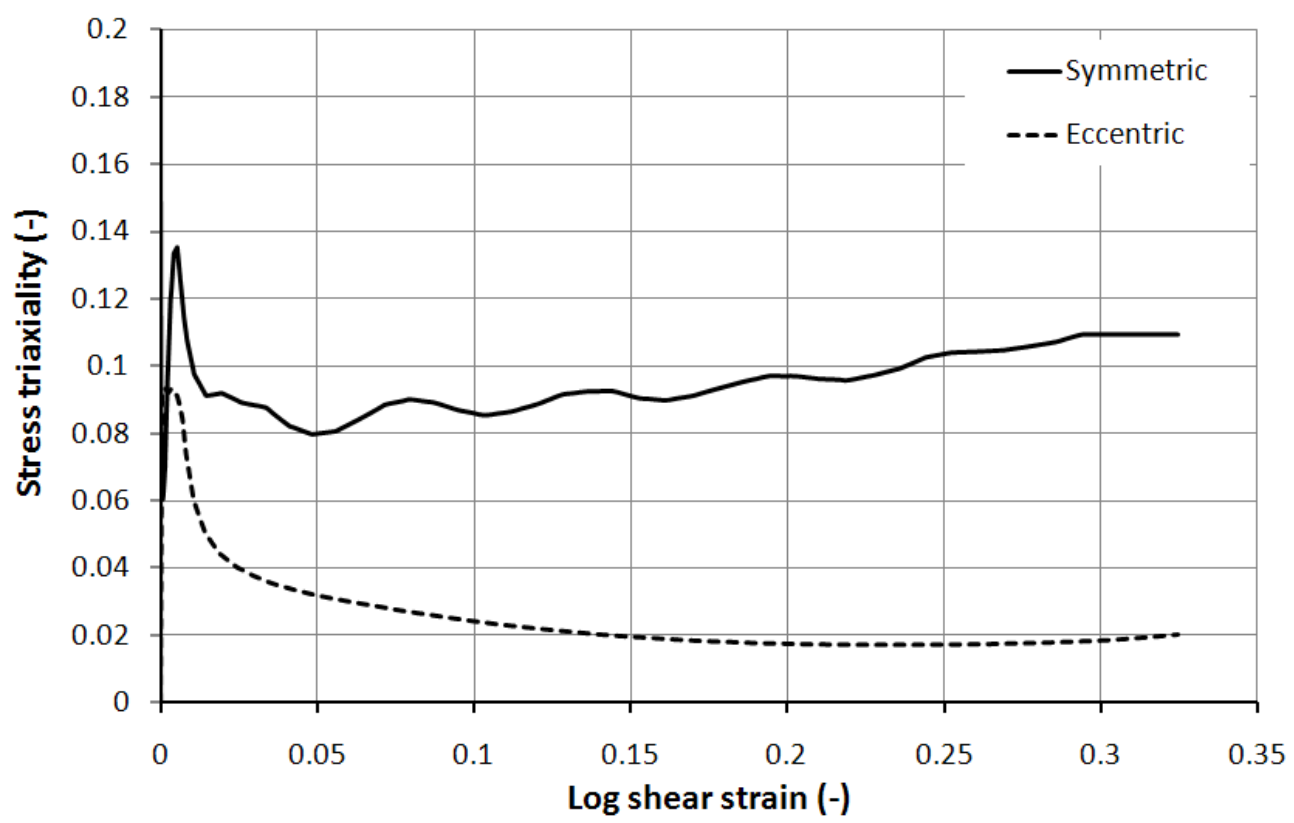

Fig. 8 Stress triaxiality for a symmetric and eccentric $(1 \mathrm{~mm})$ specimen as function of the logarithmic shear strain. The results are for a specimen with notch radius of $1 \mathrm{~mm}$

\subsection{Final design}

Taking into account the requirements listed in section 2.2 and FE simulation results presented in section 3.1, a specimen geometry with rounded eccentric positioned notches is selected (Fig. 9). A length of the shear region of $3 \mathrm{~mm}$, notch radius of $1 \mathrm{~mm}$, i.e. a geometric width of $2 \mathrm{~mm}$, and eccentricity of $1 \mathrm{~mm}$ are chosen. For the dynamic experiments, the specimen is glued into slots made in the Hopkinson bars, resulting in very low interference with the elastic tensile waves. The total length of the part subjected to the test force is only $11 \mathrm{~mm}$. Due to the design of the specimen, only a centric tensile load is required for the specimen deformation. Although only one zone is subjected to shear as opposed to the double shear test, parasitic moments on the specimen grips as in the simple shear test are avoided. A 3D FE simulation also showed that no out of plane specimen displacements occur.

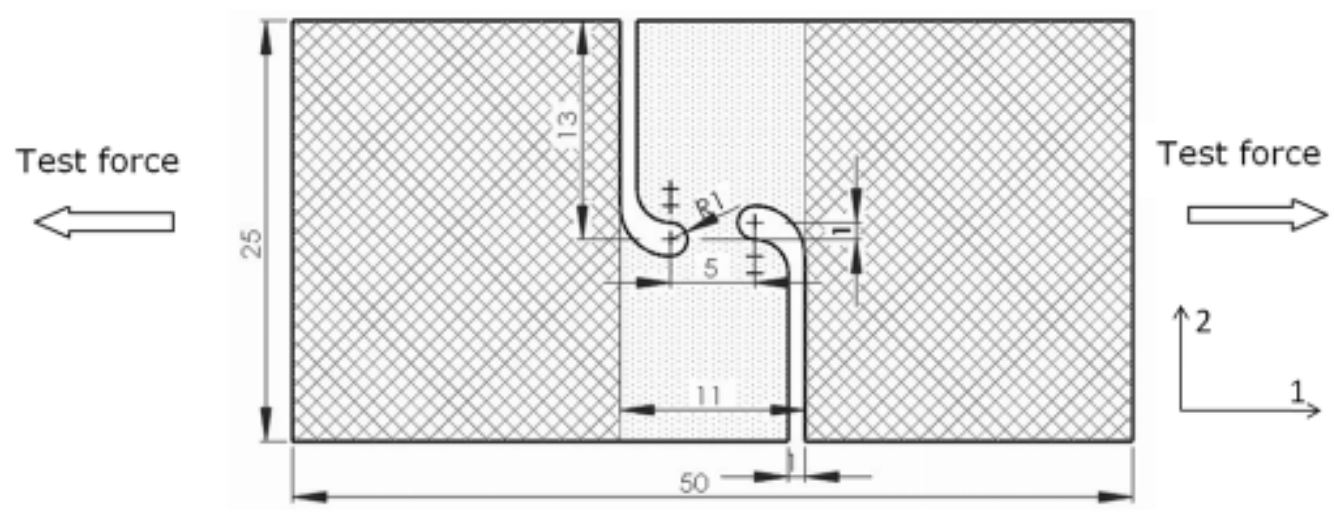

Fig. 9 Shear specimen geometry and dimensions. The eccentricity of $1 \mathrm{~mm}$ reduces the stress triaxiality in the shear region. The hatched area is glued in the slits of the Hopkinson bars 


\section{DISCUSSION}

\subsection{Determination of stress and strain}

Without additional measurements, from a static or dynamic experiment using the setups and shear geometry presented in section 2.1 and 3.2 respectively, basically the force-elongation history is obtained. The force needed for a certain specimen elongation is determined by both the specimen material and factors related to the experimental setup, such as the specimen geometry. Unlike local strains and elongations, the local stress in the shear zone and the force are directly related. Indeed, if the stress in-homogeneities near the notches are neglected, the local stress can be approximated by the average stress:

$$
\tau_{\text {ave }}=\frac{F}{L \cdot t}
$$

with $t$ the thickness of the specimen. To assess the error made by using eq. (5) to calculate the local stress, the shear stress ratio SSR is calculated from the FE simulations:

$$
S S R=\frac{\tau_{\text {ave }}}{\tau_{\text {centre }}}
$$

with $\tau_{\text {centre }}$ the local shear stress at the centre of the shear region. In Fig. 10 the SSR and the logarithmic shear strain are represented. During plastic shear deformation, the SSR is close to 1: errors of 3.5\% and 1.3\% on the local strain at 5\% and $15 \%$ of shear strain respectively are obtained using eq. (5). Errors of $1 \%$ to $4 \%$ are in the same order as found for the simple shear sample [6].

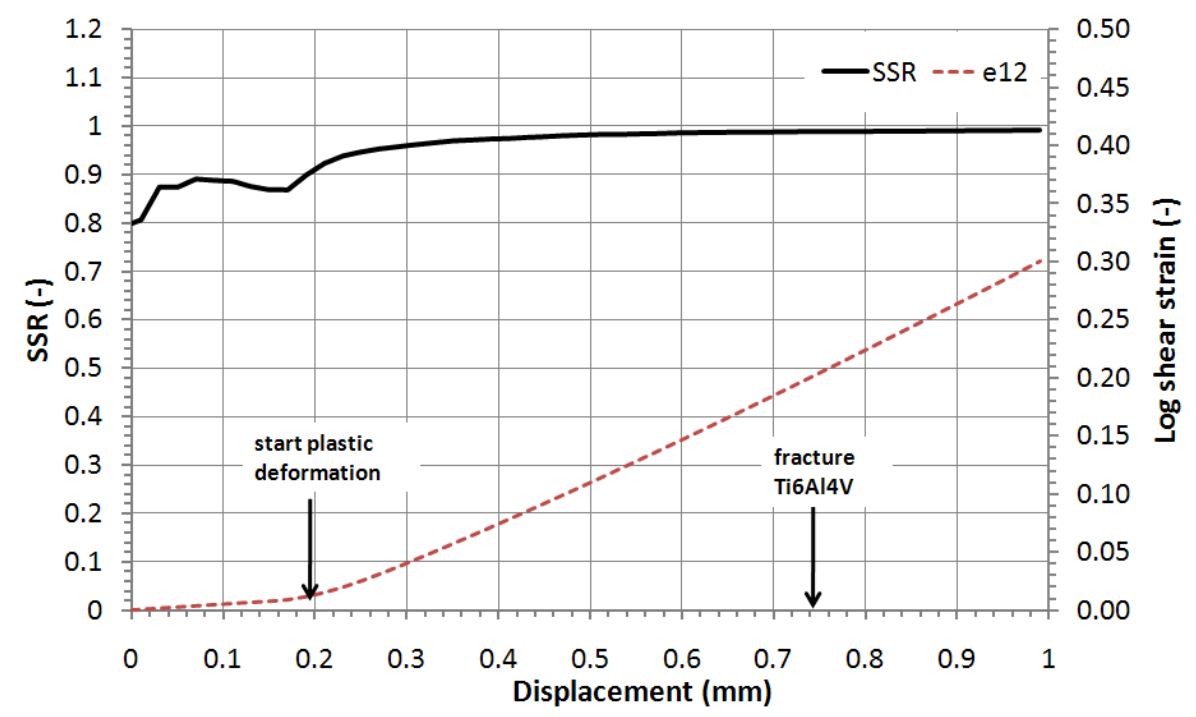

Fig. 10 Evolution of shear stress ratio (SSR) during simulated shear test with the specimen of Fig. 9. The SSR is close to 1 soon after onset of plastic deformation in the shear region. The displacement at which the entire shear region starts to deform plastically and the experimental fracture displacement for a Ti6Al4V specimen are indicated 
As mentioned, the relation between local shear strain and the specimen elongation is not straightforward. The elongation originates from the deformation of the shear zone and the adjacent material, and their relative contribution to the total elongation changes during the experiment. Figure 11 shows the ratio of the displacement increment $\Delta u^{\prime}$ to the shear strain increment $e^{\prime}{ }_{12}$. Starting from high displacement-strain increment ratios during elastic deformation, the ratio drops down at the onset of plastic deformation and further decreases, because as the deformation increases, plastic strain growth further concentrates around the line connecting the notches.

To determine the local strain either a numerical-experimental approach [27] or a local strain measurement technique should be used. Also for the simple shear test a local optical strain measurement technique is recommended [6].

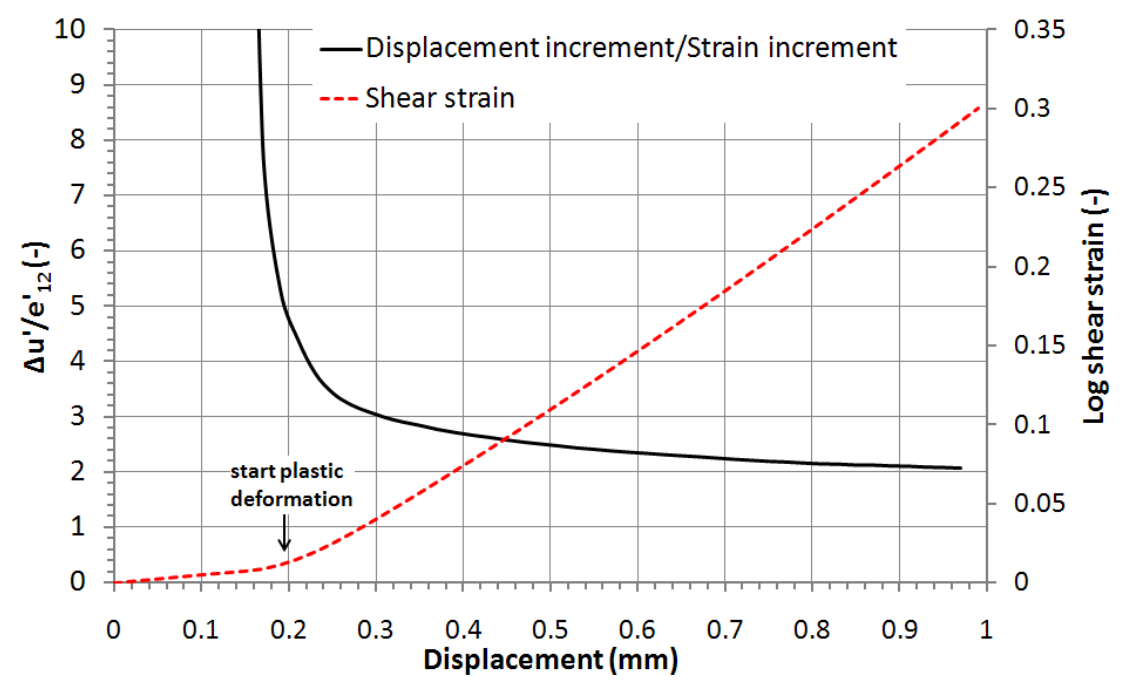

Fig. 11 Evolution of displacement - strain ratio during shear test and shear strain in the centre of the specimen as function of the displacement

\subsection{Comparison with simple shear test}

Finite element simulations are used to compare the stress states in the shear zones of the specimen presented here with the stress states in a simple shear specimen. Although, difficult to realise in practice, in the FE model of the simple shear test a perfect clamping of the shear sample is assumed. The shear region has a width of $3 \mathrm{~mm}$ and length of $30 \mathrm{~mm}$ [6]. Simulations are performed for both quasi-static and dynamic loading: a constant displacement speed is used corresponding with an average shear strain rate $\dot{e}_{12}$ of approximately $0.5 \mathrm{~s}^{-1}$ and $500 \mathrm{~s}^{-1}$ respectively. The average shear stress is calculated by (5) and the strain is the local logarithmic shear strain $e_{12}$ in the centre of the shear region. The stress-strain curves from both shear test types are shown in Fig. 13. As can be seen, a good agreement is obtained between both tests.

The small deviations between the curves can mainly be explained by differences in the stress component that is actually measured. In a simple shear specimen the strain rate tensor decomposes in a pure shear and solid rotation component:

$$
\begin{aligned}
& {\left[\begin{array}{cc}
0 & \dot{\gamma} \\
0 & 0
\end{array}\right]=\left[\begin{array}{cc}
0 & \dot{\gamma} / 2 \\
\dot{\gamma} / 2 & 0
\end{array}\right]+\left[\begin{array}{cc}
0 & \dot{\gamma} / 2 \\
-\dot{\gamma} / 2 & 0
\end{array}\right]} \\
& \text { simple shear }=\text { pure shear }+ \text { solid rotation }
\end{aligned}
$$

Consequently, the orientation of the major strain axis, initially rotated $45^{\circ}$ against the shear direction, changes during the shear test. The major tensile axis rotates towards the load direction, resulting in an increase of both the stress triaxiality and test force. Theoretically, at very high strains the shear test resembles a tensile test. For the novel specimen, because of the eccentric position of the notches, the major strain axis is initially rotated $\pm 55^{\circ}$ against the shear direction. During deformation this angle also decreases. At low strain levels the 
orientation of the major stress axes coincides with the strain axes, during deformation the major stress axes follow the same downward trend, though less pronounced compared to the strain angles. Fig. 12 shows the evolution of the orientation of the major stress and strain axes against the loading direction during dynamic deformations of the specimens. Only if the axis lies at exactly $45^{\circ}$, the shear strain $e_{12}$ and stress $\tau_{12}$, correspond with the major components $e_{I-I I}$ and $\tau_{I-I I}$. Because of the difference in orientation of the major stress axes, the shear stress $\tau_{12}$ calculated at a certain level of strain using eq. (6) is different for both geometries. For lower strain values, in the novel specimen the shear stress $\tau_{12}$ is lower than the principal shear stress $\tau_{\text {I-II }}$. At large strains, the shear stress orientation in the novel specimen is closer to $45^{\circ}$ compared with the simple shear test and the calculated stress is close to the principal shear. It is worth noting that for the calculation of the material rotation in Abaqus/Explicit, the Jaumann objective stress rate is used which is not the most accurate for large shear strains and especially for simulation of anisotropic materials [28]. However, untill $\gamma<0.8$ the difference between the material orientation calculated from different stress rate definitions is small [29].

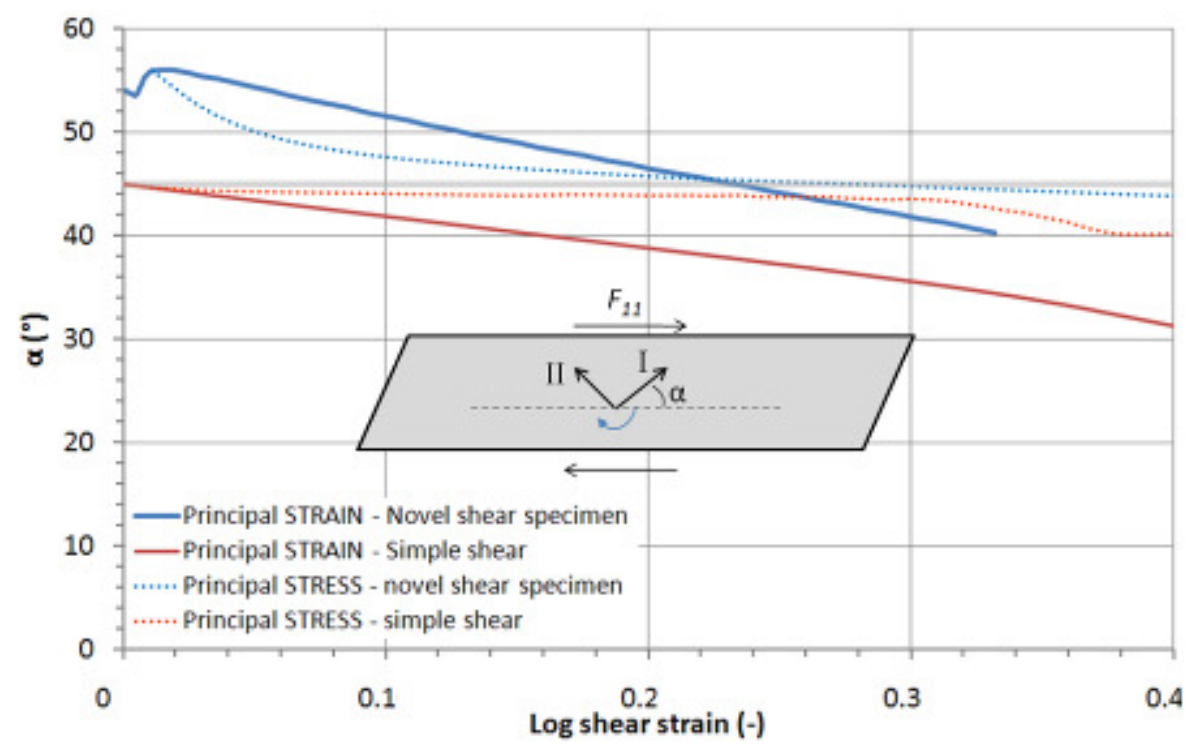

Fig. 12 Evolution of orientation of the major strain axis in the novel shear specimen and the simple shear specimen: $45^{\circ}$ is a pure shear and $0^{\circ}$ is tensile strain state

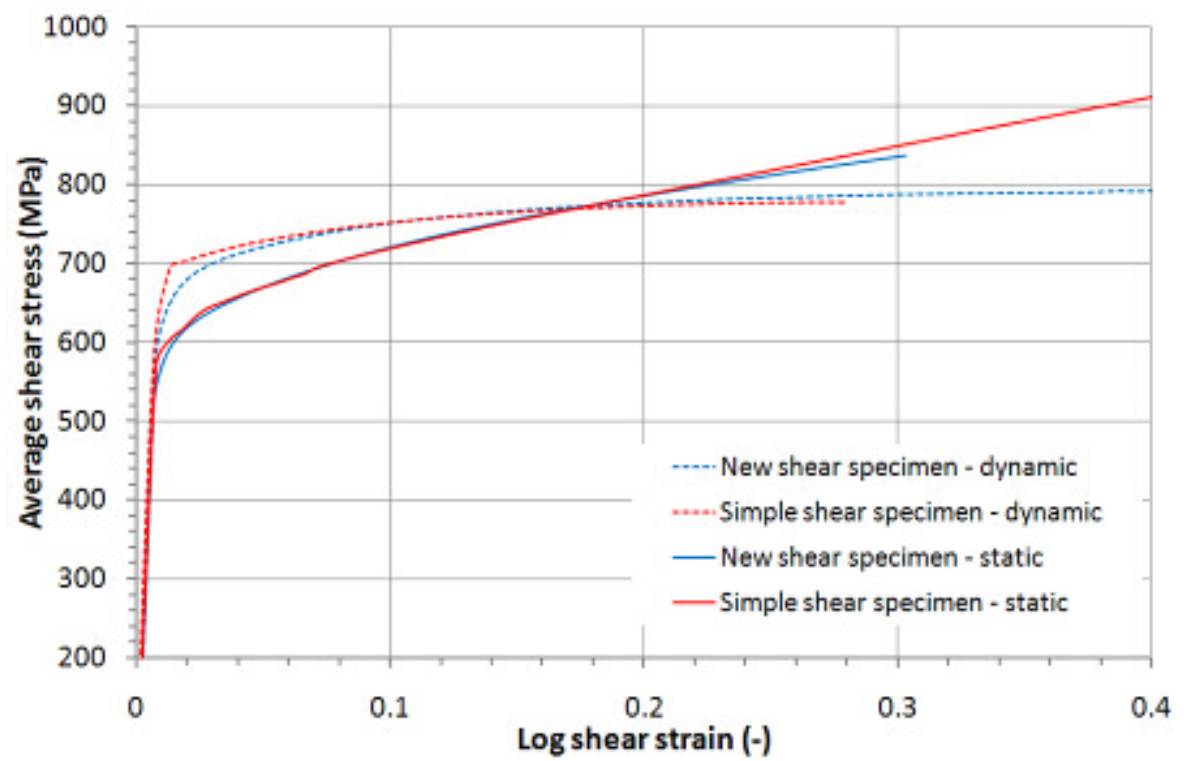

Fig. 13 Comparison of simulated stress-strain curves from the simple shear specimen and new shear specimen 


\section{SHEAR EXPERIMENTS ON TI6AL4V}

Shear specimens with the geometry of Fig. 9 are cut from a Ti6Al4V plate of $0.6 \mathrm{~mm}$ thickness by electrical discharge machining. Two series of dynamic shear experiments are performed: with the axis of the specimens in the rolling direction (RD) and in the transverse direction (TD). When the incident loading wave reaches the specimen, the relative speed of the specimen/bar interfaces is rapidly rising to reach an approximately constant value during plastic deformation of the shear zone. Next to the dynamic tests, a static test is carried out.

Figure 14 shows successive high speed camera images of the shear region during a dynamic test. For this test the specimen/bar interfaces separate with a speed of approximately $2.7 \mathrm{~m} / \mathrm{s}$. The figure clearly shows that the line connecting the notch tips, is rotating clockwise. From these pictures the local shear strain is calculated using digital image correlation; results are presented in Fig. 16 and 16. Next to the DIC strain, also the simulated strain field is represented in Fig. 16. As can be seen, good qualitative and quantitative correspondence is found between the experimental and simulated strain. Fig. 15 shows images of a specimen with line grating during a static test. The angle between the grid lines and the vertical direction is a measure for the local shear angle. Just before fracture, a local maximum engineering shear strain $\gamma$ of approximately 0.85 is observed, corresponding with a logarithmic strain of $e_{12}$ of $38 \%$ if simple shear is assumed (eq. (5)). It is clear that there is only large plastic deformation in the region between the notches. The width of the plastically deforming region is slightly smaller than the notch diameter and remains more or less constant during the test, however strain gradients along the width of the shear region increase. Near fracture, sharp corners arise in the notches. However, the compressive stress state at the corners prevents the onset of the fracture at this location. The final fracture starts around the centre of the specimen and is in line with the tensile direction. 


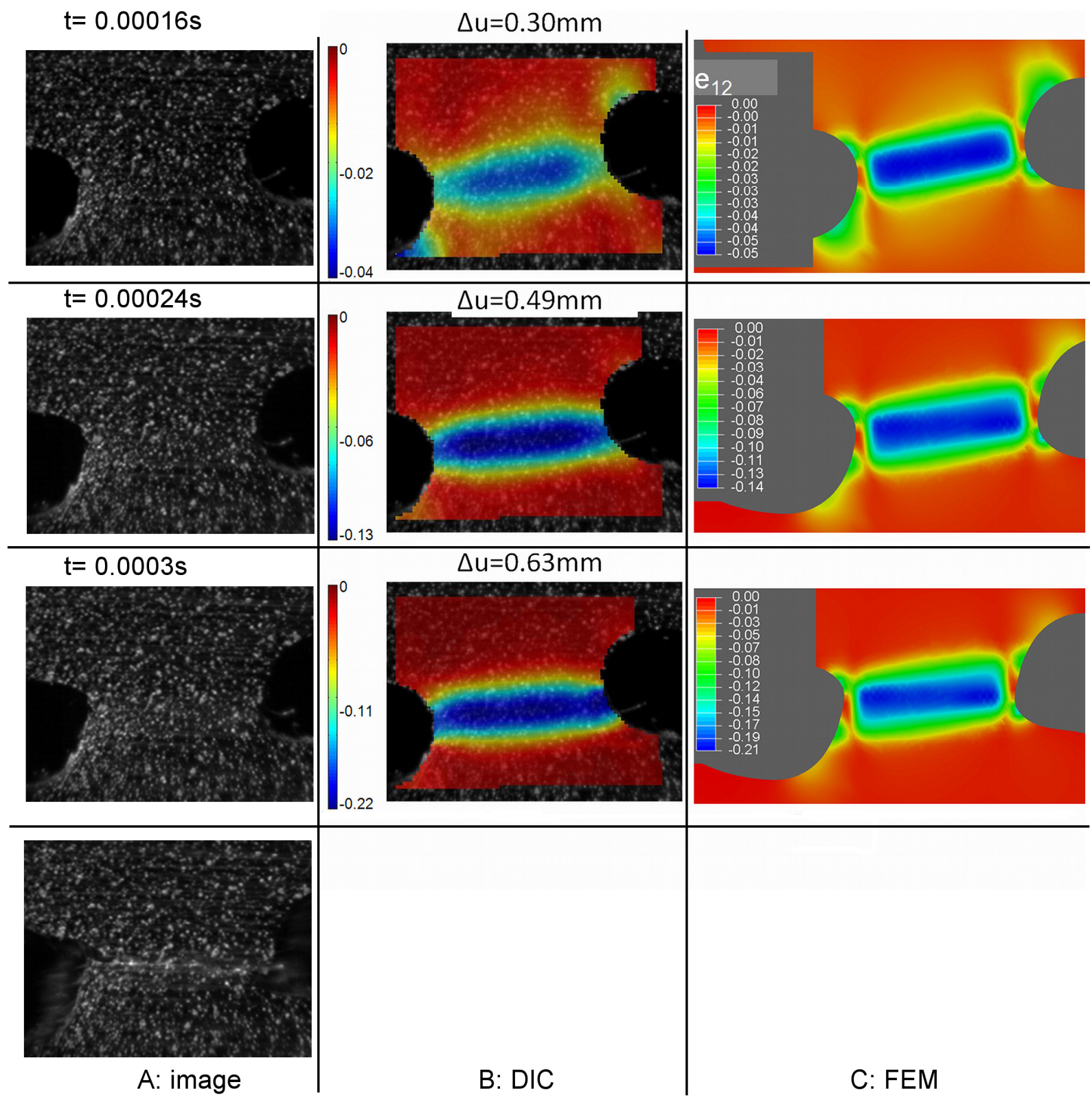

Fig. 14 Sequence of images of the deforming shear region with speckle pattern during a dynamic test (a), corresponding logarithmic shear strain calculated with DIC (b) and FE simulated logarithmic shear strain (c) 


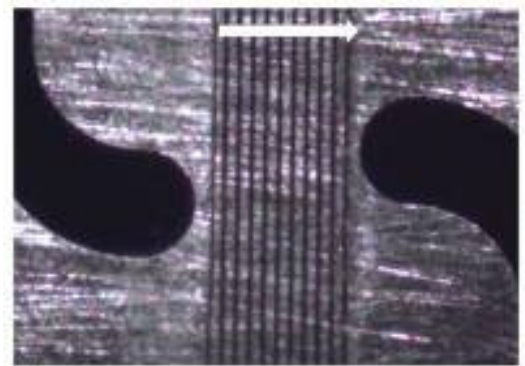

$\mathrm{t}=0 \mathrm{~s}$

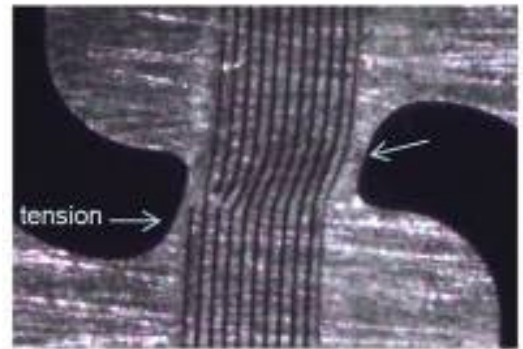

$\mathrm{t}=275 \mathrm{~s}$

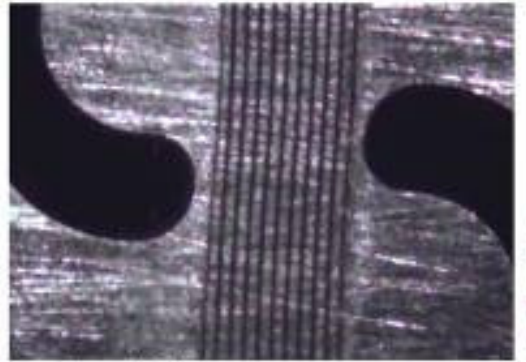

$t=125 s$

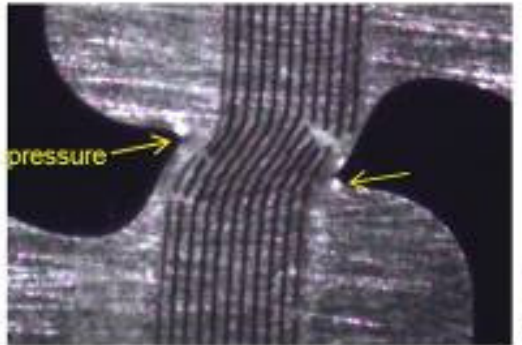

$\mathrm{t}=350 \mathrm{~s}$

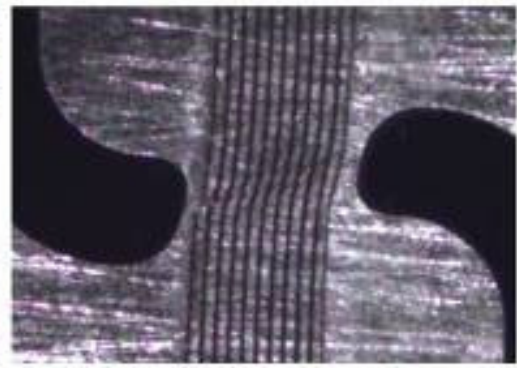

$t=200 s$

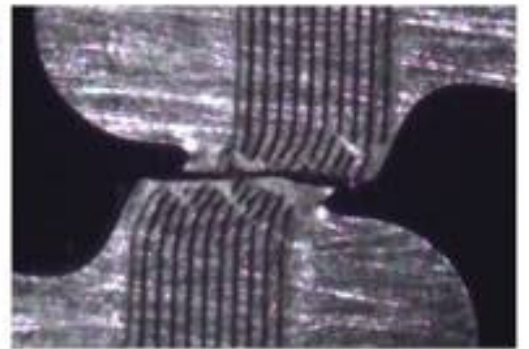

$t=425 s$

Fig. 15 Sequence of images of the deforming shear region with line grid during static test

The force-displacement curves of two typical dynamic experiments and a static experiment are shown in Fig. 16. The corresponding local logarithmic shear strains in the centre of the shear region, calculated with DIC and FE simulations, are also provided.

Two parts can easily be distinguished in the curves from the dynamic experiments. At the onset of loading, the specimen mainly deforms elastically, the strain in the shear region is limited and only at the notches plastic deformation occurs. At a displacement of $0.2 \mathrm{~mm}$, the material in the shear region starts to yield and further plastic deformation concentrates in the shear region.

All experiments finish by an abrupt drop in the force; no necking occurs before fracture in shear tests and high strains are reached. The local logarithmic shear strain at fracture obtained by DIC is above $25 \%$ for dynamic tests and above $35 \%$ for static tests, which is indeed much higher than the uniform strain achieved in tensile tests on Ti6A14V. The difference between the RD and TD specimens is found in the displacement at fracture and is the result of texture-induced anisotropy. The stress level in the static test is lower than in the dynamic test.

Simulated force-displacement curves are also presented in Fig. 16. Two parameter sets of the JC material model are used: the parameters used for the design of the specimen and an improved parameter set obtained using the experimental results itself. It is seen that by using the appropriate model parameters, the plastic deformation of the specimen is well predicted by the FE model. 

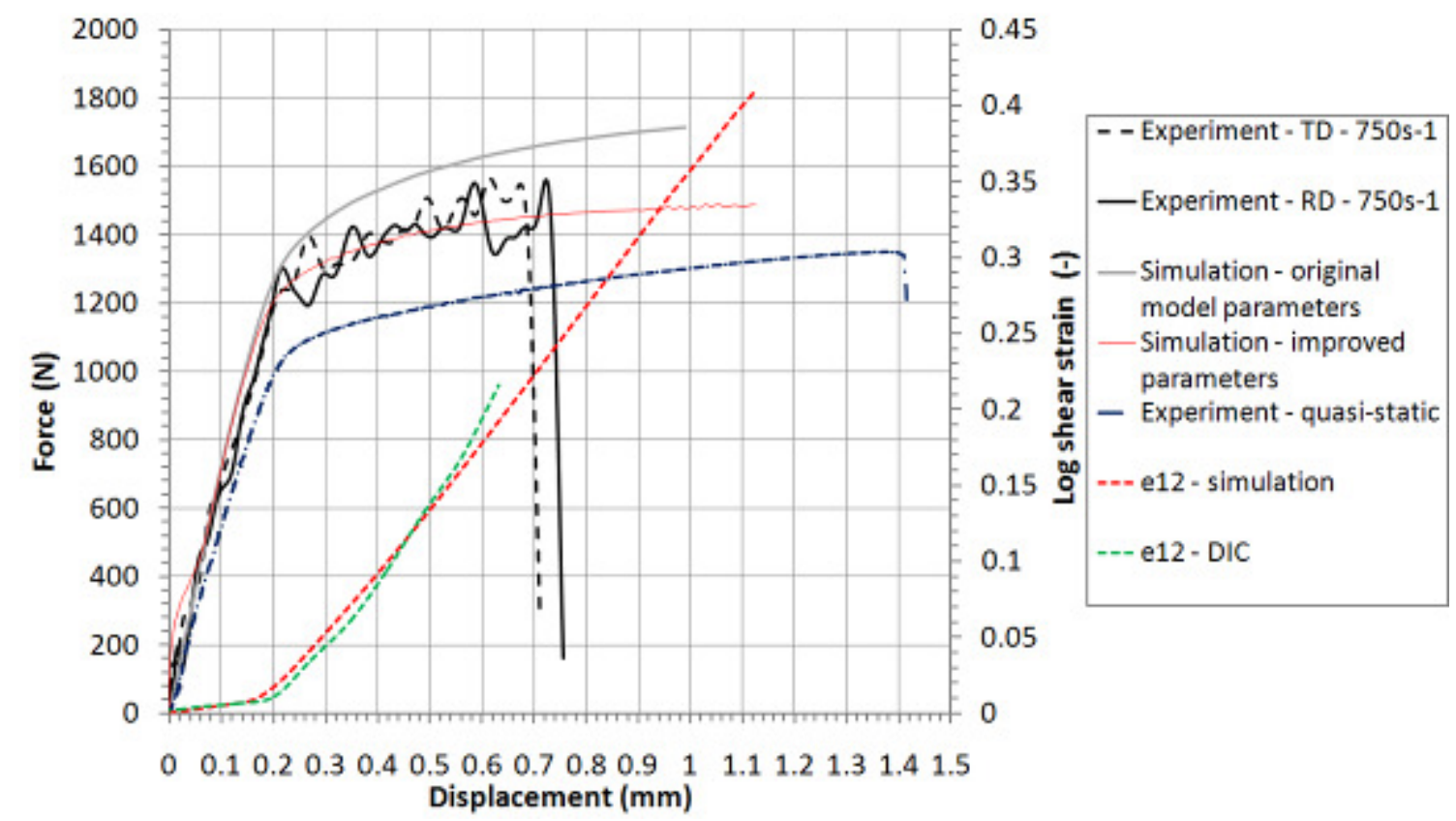

Fig. 16 Experimental and simulated force-displacement curves for dynamic and static shear experiments on Ti6Al4V. DIC and simulated logarithmic shear strains in the centre are presented on the secondary vertical axis

\section{CONCLUSIONS}

A test technique to characterize the static and dynamic shear behaviour of sheet metals is presented using both a traditional tensile test device and a split Hopkinson tensile bar setup. Essential for the test technique is the use of an appropriate specimen geometry. Starting from geometries found in literature, the here proposed novel shear specimen geometry is developed using finite element simulations. To fix the specimen in the test setup, no clamps are needed. As a result, oscillations and erroneous measurements of forces and elongations in the dynamic experiments are avoided. Moreover, early rupture and buckling at the borders of the shear region and slip in the clamps are also avoided, thus ensuring a high repeatability of the test results. The small dimensions guarantee a state of quasi-static equilibrium desired in a split Hopkinson bar experiment. The most important new feature of the specimen is found in the eccentric position of the notches which leads to an almost pure-shear stress state up to large strains. It is found that the local stress in the shear zone is directly related to the measured test load.

Static and dynamic experiments have been carried out on a Ti6Al4V sheet. Digital image correlation is used to obtain information about the local strain. The results show that indeed higher strains are reached in the shear tests compared to tensile tests. The shear strain in the dynamically loaded specimen is lower than in the statically loaded specimen. As desired, the final crack starts within the central part of the specimen, not at the edges.

\section{ACKNOWLEDGMENTS}

The authors acknowledge the technical support of Dr. P. Lava and Dr. D. Debruyne from the Catholic University College Ghent for their in-house developed image correlation software MatchID. Furthermore, the authors would like to acknowledge funding of The Interuniversity Attraction Poles Program (IUAP) of the Federal Science Policy of Belgium and the partners of IUAP-VI (www.m3phys.be).

\section{REFERENCES}

1. Tarigopula V, Hopperstad OS, Langseth M, Clausen AH, Hild F, Lademo OG, Eriksson M (2008) A study of large plastic deformations in dual phase steel using digital image correlation and FE analysis. Exp Mech 48 (2):181-196. doi:10.1007/s11340-007-9066-4 
2. Lademo OG, Engler O, Keller S, Berstad T, Pedersen KO, Hopperstad OS (2009) Identification and validation of constitutive model and fracture criterion for AlMgSi alloy with application to sheet forming. Materials \& Design 30 (8):3005-3019. doi:10.1016/j.matdes.2008.12.020

3. Rusinek A, Klepaczko JR (2001) Shear testing of a sheet steel at wide range of strain rates and a constitutive relation with strain-rate and temperature dependence of the flow stress. Int J Plasticity 17 (1):87-115. doi:10.1016/S0749-6419(00)00020-6

4. Klepaczko JR, Nguyen HV, Nowacki WK (1999) Quasi-static and dynamic shearing of sheet metals. European Journal of Mechanics a-Solids 18 (2):271-289. doi:10.1016/S0997-7538(99)80016-3

5. Rauch EF (2009) Plastic behavior of metals at large strains: experimental studies involving simple shear. J Eng Mater Technol 131 (1):011107 (011108pp.). doi:10.1115/1.3030942

6. Bouvier S, Haddadi H, Levee P, Teodosiu C (2006) Simple shear tests: Experimental techniques and characterization of the plastic anisotropy of rolled sheets at large strains. J Mat Proc Tech 172 (1):96-103. doi:1016/j.jmatprotec.2005.09.003

7. Inal K, Wu PD, Neale KW (2002) Large strain behaviour of aluminium sheets subjected to in-plane simple shear. Modelling and Simulation in Materials Science and Engineering 10 (2):237-252

8. Bacroix B, Genevois P, Teodosiu C (1994) Plastic anisotropy in low-carbon steels subjected to simple shear with strain path changes. European Journal of Mechanics a-Solids 13 (5):661-675

9. Klepaczko JR (1994) An experimental-technique for shear testing at high and very high-strain rates - the case of a mild-steel. Int J Impact Eng 15 (1):25-39

10. Miyauchi K (1984) A proposal of a planar simple shear test in sheet metals. Scientific Papers of the Institute of Physical and Chemical ResearchlScientific Papers of the Institute of Physical and Chemical Research 78 (3):27-40

11. Gaspérini M, Pinna C, Swiatnicki W (1996) Microstructure evolution and strain localization during shear deformation of an aluminium alloy. Acta Materialia 44 (10):4195-4208. doi:10.1016/S13596454(96)00046-8

12. Merle R, Zhao H (2004) Experimental study of sheet metals under dynamic double shear at large strains. Advances in Eng Plast and its Appl, Pts 1 and 2 274-276:787-792

13. Harding $\mathrm{J}$, Huddart $\mathrm{J}$ The use of the double-notch shear test in determining the mechanical properties of uranium at very high rates of strain. In: Harding J (ed), 1980. pp 49-61

14. Bonnet-Lebouvier AS, Klepaczko JR (2002) Numerical study of shear deformation in Ti-6Al-4V at medium and high strain rates, critical impact velocity in shear. Int J Impact Eng 27 (7):755-769

15. Chwalik P, Klepaczko JR, Rusinek A Impact shear-numerical analyses of ASB evolution and failure for Ti-6Al-4V alloy. In: 7th International Conference on Mechanical and Physical Behaviour of Materials Under Dynamic Loading, Oporto, Portugal, Sep 08-12 2003. pp 257-262. doi:10.1051/jp4:20030703

16. Bouvier S, Gardey B, Haddadi H, Teodosiu C (2006) Characterization of the strain-induced plastic anisotropy of rolled sheets by using sequences of simple shear and uniaxial tensile tests. J Mat Proc Tech 174 (1-3):115-126. doi:10.1016/j.jmatprotec.2005.04.086

17. Bao YB, Wierzbicki T (2004) On fracture locus in the equivalent strain and stress triaxiality space. Int $J$ of Mech Sciences 46 (1):81-98. doi:10.1016/j.jimecsci.2004.02.006

18. Carney KS, Pereira JM, Revilock DM, Matheny P (2009) Jet engine fan blade containment using an alternate geometry. Int J Impact Eng 36 (5):720-728. doi:10.1016/j.ijimpeng.2008.10.002

19. Kolsky H (1949) An investigation of the mechanical properties of materials at very high rates of loading. Proceedings of the Physical Society 62:676-700

20. Verleysen P, Degrieck J (2004) Experimental investigation of the deformation of Hopkinson bar specimens. Int J Impact Eng 30 (3):239-253. doi:10.1016/s0734-743x(03)00069-1

21. Gsell C, Boni S, Shrivastava S (1983) Application of the plane simple shear test for determination of the plastic behavior of solid polymers at large strains. Journal of Materials Science 18 (3):903-918

22. Dey S, Borvik T, Hopperstad OS, Langseth M (2007) On the influence of constitutive relation in projectile impact of steel plates. Int J Impact Eng 34 (3):464-486. doi:10.1016/j.ijimpeng.2005.10.003

23. Coghe F, Rabet L, Kestens L (2006) Deformation mechanism of a commercial titanium alloy Ti6Al4V as a function of strain rate and initial texture. J Phys IV 134:845-850. doi:10.1051

24. Kapoor R, Nemat-Nasser S (1998) Determination of temperature rise during high strain rate deformation. Mechanics of Materials 27 (1):1-12 
25. Lava P, Cooreman S, Coppieters S, De Strycker M, Debruyne D (2009) Assessment of measuring errors in DIC using deformation fields generated by plastic FEA. Optics and Lasers in Engineering 47 (7-8):747753. doi:10.1016/j.optlaseng.2009.03.007

26. Ziolkowski A (2006) Simple shear test in identification of constitutive behaviour of materials submitted to large deformations - hyperelastic materials case. Eng Trans 54 (4):251-269

27. Peirs J, Verleysen P, Van Paepegem W, Degrieck J Combined experimental and numerical approach for identification of dynamic material model parameters. In: Bremand F (ed) ICEM14, Poitiers, 2010. EDP Sciences

28. Duchêne L, Lelotte T, Flores P, Bouvier S, Habraken AM (2008) Rotation of axes for anisotropic metal in FEM simulations. Int J Plasticity 24 (3):397-427. doi:10.1016/j.ijplas.2007.03.015

29. de Montleau P, Habraken AM, Duchêne L (2008) A new finite element integration scheme. Application to a simple shear test of anisotropic material. International Journal for Numerical Methods in Engineering 73 (10):1395-1412. doi:10.1002/nme.2130 